\title{
Fishing in the thoracic organ donor pool: What next if the catch of the day got infected with hepatitis $\mathrm{C}$ virus?
}

Dirk Van Raemdonck, MD, PhD, ${ }^{\mathrm{a}, \mathrm{b}}$ Frederik Nevens, MD, PhD, ${ }^{\mathrm{b}, \mathrm{c}}$ Johan Van Cleemput, MD, PhD, Robin Vos, MD, PhD, ${ }^{\mathrm{b}, \mathrm{f}}$ Arne Neyrinck, MD, PhD, ${ }^{\mathrm{e}, \mathrm{g}}$ and Geert M. Verleden, MD, $\mathrm{PhD}^{\mathrm{b}, \mathrm{f}}$

\section{Feature Editor's Introduction-Lung transplantation} has become standard of care for patients with endstage respiratory failure. The gap between demand and availability of suitable donor organs continues to result in substantial mortality for patients whose only option is the waiting list; however, the real lung donor pool may be incompletely discovered. Recent and ongoing advances in lung transplantation that could expand the number of donor lungs include the use of extendedcriteria organs, resuscitation of marginal organs with ex vivo lung perfusion, and living lobar lung transplantation. Whereas the use of lungs from donors with chronic viral infections, including hepatitis $C$ virus $(\mathrm{HCV})$ infection, has traditionally been contraindicated for transplantation into uninfected recipients, this practice has recently been challenged by the advent of curative antiviral therapy and the bold implantation of $\mathrm{HCV}^{+}$organs into $\mathrm{HCV}^{-}$recipients treated with these antiviral drugs. This new horizon for expanding the usability of donor lungs was recently showcased in a clinical trial published in the New England Journal of Medicine and is nicely framed in this Feature Expert Opinion article. Herein the benefits of expanding a currently insufficient donor supply are cautiously balanced by an account of its inherent risks, such as the transmission of a chronic viral infection into an immunosuppressed individual and the possibility of consequent allograft dysfunction. Transplant surgeons will appreciate the authors' considerations regarding donor offers and informed consent, and all readers are offered a glimpse of the face of innovation.

\section{Bryan M. Burt, MD}

\footnotetext{
From the Departments of ${ }^{\mathrm{a}}$ Thoracic Surgery, ${ }^{\mathrm{c}}$ Gastroenterology and Hepatology, ${ }^{\mathrm{d}}$ Cardiology, ${ }^{\mathrm{f}}$ Pneumology, and ${ }^{\mathrm{g}}$ Anesthesiology, University Hospitals Leuven; and Departments of ${ }^{\mathrm{b}}$ Chronic Diseases, Metabolism, and Ageing, and ${ }^{\mathrm{e}}$ Cardiovascular Sciences, Catholic University Leuven, Leuven, Belgium.

Received for publication June 3, 2019; revisions received Aug 9, 2019; accepted for publication Aug 14, 2019; available ahead of print Dec 16, 2019.

Address for reprints: Dirk Van Raemdonck, MD, PhD, Department of Thoracic Surgery, University Hospital Gasthuisberg, Herestraat 49, B-3000 Leuven, Belgium (E-mail: dirk.vanraemdonck@uzleuven.be).

J Thorac Cardiovasc Surg 2020;159:2121-5 $0022-5223 / \$ 36.00$

Copyright $(2019$ Published by Elsevier Inc. on behalf of The American Association for Thoracic Surgery

https://doi.org/10.1016/j.jtcvs.2019.08.140
}

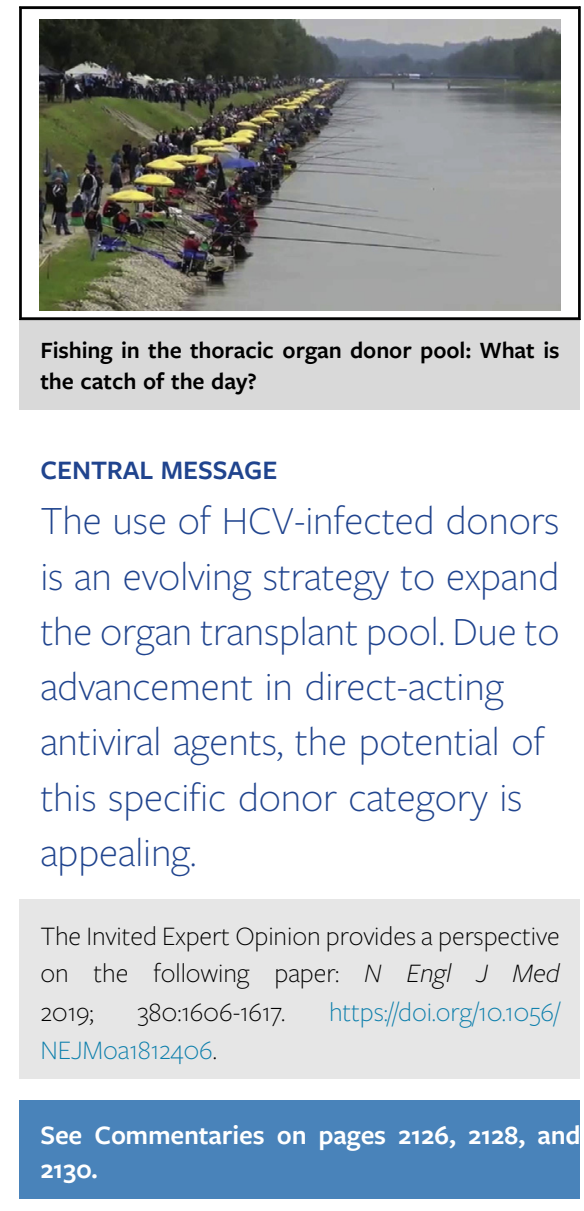

THORACIC TRANSPLANTATION SUFFERS FROM A CRITICAL ORGAN SHORTAGE

Thoracic transplantation remains the ultimate treatment for patients suffering from end-stage native heart and/or lung failure refractory to medical management, offering improved survival and enhanced quality of life. Over the last 3 decades, both heart transplantation (HTx) and lung transplantation (LTx) have enjoyed increasing success, with improving early and late survival. ${ }^{1,2}$ The number of qualifying transplant candidates by far outpaces the amount of suitable donors and transplantable thoracic organs, however. In 2017, 3769 HTx and 2901 LTx candidates were newly registered on the waiting list in the United States, and 3273 HTxs and 2478 LTxs were performed, whereas $290(7.7 \%)$ HTx candidates and 214 $(7.4 \%)$ LTx candidates died awaiting a suitable organ offer. $^{3,4}$ 


\section{FISHING IN THE ORGAN DONOR POOL}

As scarcity of good-quality organs continues to be a challenge, the thoracic transplantation community has constantly explored new avenues to enlarge the organ donor pool through the use of extended-criteria heart ${ }^{5}$ and lung donors ${ }^{6}$ and living lobar $\mathrm{LTx}^{7}$ with good recipient outcomes. More recently, successful transplantation of hearts ${ }^{8}$ and lungs ${ }^{9}$ recovered from donors after circulatory death has been reported, including donation from euthanasia patients.

The recent worsening opioid epidemic in the United States has resulted in an increase in the number of HTxs and LTxs from overdose-death donors, now accounting for nearly $20 \%$ of all donors in some areas of the country. Under US Public Health Service (PHS) guidelines, these donors are considered as conveying an increased risk because of the higher prevalence of donor intravenous drug abuse and the associated risks for blood-borne infections such as hepatitis B virus (HBV), hepatitis $\mathrm{C}$ virus (HCV), human immunodeficiency virus (HIV), candidemia, and endocarditis. The prevalence of HCV in young intravenous drug abusers with $<5$ years of use is estimated to be $20 \%$ to $46 \%$.

Previous studies have suggested that organs from increased-risk donors are used at lower rates than organs from standard-risk donors. ${ }^{10}$ In a recent analysis looking at data on adult HTxs from 2010 to 2017 provided by the Scientific Registry of Transplant Recipients, $63.3 \%$ of discarded hearts were categorized as US Public Health Service increased infectious risk despite favorable indices of good cardiac function. ${ }^{11}$ These findings support a call to action to set up studies exploring treatment strategies for safe use of allografts from otherwise healthy increased-risk donors.

\section{TIME TO GO VIRAL?}

For many years, viremic organ donors have been listed as an absolute contraindication for transplantation into uninfected recipients because of the risk for transmission of a specific viral disease, such as cytomegalovirus (CMV), HIV, HBV, or HCV. Beside the morbidity related to an acute viral infection, the development of a chronic viral diseases in an immunosuppressed recipient may result in accelerated graft damage, need for retransplantation, and lower survival. This credendum was challenged more recently when safe and effective antiviral therapy became available.

Zamora and colleagues ${ }^{12}$ reported that valganciclovir is safe and effective for the prevention of CMV infection after $\mathrm{LTx}$ from $\mathrm{CMV}^{+}$donors into $\mathrm{CMV}^{-}$or $\mathrm{CMV}^{+}$recipients following universal prophylaxis with intravenous ganciclovir and CMV immune globulin. ${ }^{12}$

The American Society of Transplantation (AST) has developed guidelines for solid organ transplantation in
HIV-infected patients. $\mathrm{HIV}^{+}$donors may provide support for using these organs for $\mathrm{HIV}^{+}$patients in urgent need of transplantation. ${ }^{13}$

The use of organs from $\mathrm{HBV}^{+}$donors may also expand the donor pool. However, it is important to use consistent and correct terminology regarding the definition of an $\mathrm{HBV}^{+}$donor. Transmission occurs if the donor is HBV surface antigen-positive $\left(\mathrm{HBVsAG}^{+}\right)$because of viral DNA circulation. Positive serology with HBVcore antibodypositive $\left(\mathrm{HBV} \mathrm{AB}^{+}\right)$indicates natural contact with the virus in the past. There is no risk of using allografts from $\mathrm{HBVcAB}^{+} / \mathrm{HBVsAG}^{-}$donors except for liver transplantation, because the donor liver might be a reservoir of viral DNA. The AST convened a multidisciplinary expert panel that reviewed the existing literature and developed consensus recommendations for recipient management following the use of organs from $\mathrm{HBV}^{+}$donors. They confirmed that the transmission risk is highest with liver donors and significantly lower with non-liver (kidney and thoracic) donors. In the event that these livers are used for transplantation, antiviral prophylaxis significantly reduces the rate of transmission to liver recipients from isolated $\mathrm{HBVcAB}^{+}$donors. ${ }^{14}$ In a search on the use of $\mathrm{HBVcAB}^{+}$ donors, White and colleagues ${ }^{15}$ found only a single case of HBV transmission to an $\mathrm{HBVsAg}^{-}$HTx recipient who did not receive prophylaxis out of 122 adult HTx/HTxLTx recipients reported in the literature. In adults, the risk of transmission from an $\mathrm{HBVcAB}^{+}$donor is rather low if vaccination has been successfully completed, as witnessed by the development of $\mathrm{HBVsAB}^{+}$in the candidate before transplantation. Moreover, if contamination occurs, effective treatment for $\mathrm{HBV}$ is available.

Until recently, the use of $\mathrm{HCV}$-infected organ donors for uninfected recipients was a controversial, yet rapidly evolving area once highly effective and safe direct-acting antiviral (DAA) therapy became available. These agents act as small-molecule inhibitors of the HCV viral replication cycle that target nonstructural viral proteins. The advent of DAA treatment has drastically changed the landscape of HCV treatment. The cure rate is almost $100 \%$, even in patients under immunosuppression, and these drugs are well tolerated. DAA treatment still poses challenges, however. Some agents may treat only some of the genotypes, whereas others have pangenotypic efficacy, avoiding the need for blood sampling for genotype assessment preoperatively. In addition, agents have different absorption properties when administered orally or via a nasogastric tube, so that initiation of treatment may be delayed. Some drugs are not allowed in cases of renal impairment, which is often seen in transplant recipients. Most importantly, however, all agents have significant drug interactions with other medications that may create problems in the posttransplantation period. Nevertheless, the use of organs from $\mathrm{HCV}^{+}$donors may further expand the donor pool. 
Similar as for $\mathrm{HBV}$, it is important to distinguish $\mathrm{HCV}^{+}$donors with nucleic acid amplification test (NAT)-positive $\left(\mathrm{HCV} \mathrm{RNA}^{+}\right.$) from those with positive serology only $\left(\mathrm{HCV} \mathrm{AB}^{+} / \mathrm{RNA}^{-}\right)$as a result of previous viral contact. Recipients of grafts from $\mathrm{HCV} \mathrm{AB}^{+} / \mathrm{RNA}^{+}$(viremic) donors have a $100 \%$ risk of disease transmission, compared with $5 \%$ for $\mathrm{HCV} \mathrm{AB}^{+} / \mathrm{RNA}^{-}$donors.

\section{EXPERIENCE WITH ORGAN TRANSPLANTATION FROM HCV ${ }^{+}$DONORS}

Pilot studies on transplantation of $\mathrm{HCV}^{+}$kidney grafts into $\mathrm{HCV}^{-}$recipients within the frame of a well-defined protocol with access to DAA treatment have suggested that this is a potentially important strategy for increasing the kidney donor pool, associated with excellent allograft function with cure of $\mathrm{HCV}$ infection. ${ }^{16,17}$ Because the liver is the major reservoir of $\mathrm{HCV}$ and the main site of $\mathrm{HCV}$ replication, transmission of the infection with liver transplantation is almost $100 \%$. Therefore, the quality of the liver grafts from $\mathrm{HCV}^{+}$donors should be evaluated carefully, as chronic HCV infection post-transplantation may rapidly progress to cirrhosis and fibrotic cholestatic hepatitis, a rare but lethal complication. The majority of LTx recipients from $\mathrm{HCV}^{+}$donors were known to be or to have been $\mathrm{HCV}^{+}$. To date, few studies have reported on the use of $\mathrm{HCV}^{+}$liver donors for $\mathrm{HCV}^{-}$recipients. ${ }^{18,19}$

Experience with thoracic organ transplantation from $\mathrm{HCV}^{+}$donors is rapidly accumulating in the DAA era. ${ }^{20}$ A case series describing outcomes in 13 uninfected recipients undergoing HTx from HCV $\mathrm{RNA}^{+}$donors between September 2016 and March 2017 was reported by a Vanderbilt University group. ${ }^{21}$ Nine of 13 patients $(69 \%)$ developed HCV viremia after transplantation, including 8 who completed DAA treatment and demonstrated cure, as defined by a sustained virologic response at 12 weeks after treatment.

Another case series reporting outcomes in $5 \mathrm{HCV}^{\mathrm{RNA}}{ }^{-}$ recipients undergoing LTx from HCV $\mathrm{RNA}^{+}$donors between November 2016 and February 2017 was reported by the authors at the University of Alberta. ${ }^{22}$ Despite the severity of illness at transplantation and numerous posttransplantation complications, resulting in delayed initiation of DAA therapy, all recipients were cured, without any adverse effects attributable to either the acquired HCV infection or the DAA therapy. In a recent study from Radzi and coworkers, ${ }^{23}$ outcome was reported after pediatric $\mathrm{HTx}$ from $\mathrm{HBV}^{+}$or $\mathrm{HCV}^{+}$donors into 12 seronegative recipients in the United Network for Organ Sharing database between June 2008 and June 2015. Using propensity score models, outcomes were compared between $\mathrm{HCV}^{+}$or $\mathrm{HBVCAB}^{+}$donors into $\mathrm{HCV}^{-}$and $\mathrm{HBVcAB}^{-}$recipients and $\mathrm{HCV}^{-}$or $\mathrm{HBVcAB}^{-}$donors and recipients. Post-transplantation 5-year graft survival was similar for the 3 recipients of $\mathrm{HCV}^{+}$donor hearts and
9 recipients of $\mathrm{HCV}^{-}$donor hearts $(67 \%$ vs $88 \%$; $P=.44)$, with 1 death due to respiratory failure. Nine $\mathrm{HBV}_{\mathrm{CAB}}{ }^{+}$donor hearts were transplanted in $\mathrm{HBVcAB}^{-}$ and $\mathrm{HBVsAg}^{-}$recipients. Post-transplantation 5-year graft survival was similar to that of 27 recipients with $\mathrm{HBVcAB}^{-}$ donors $(87 \%$ vs $91 \% ; P=.81)$, with 1 death due to multiple system organ failure. In the same United Network for Organ Sharing database, 2203 potential yet unused $\mathrm{HCV}^{+}$or $\mathrm{HBVcAB}^{+}$donors were identified. This high number underlines the potential of this specific donor category for thoracic transplantation.

Recently, Woolley and colleagues ${ }^{24}$ from Brigham and Women's Hospital reported on a trial involving successful transplantation of hearts and lungs from $\mathrm{HCV} \mathrm{RNA}{ }^{+}$donors into $\mathrm{HCV} \mathrm{RNA}^{-}$recipients. This open-label pilot trial was conducted in the Donors of Hepatitis C NAT (nucleic acid amplification test)-Positive Thoracic Allografts for Transplantation Evaluation in Non-HCV Recipients (DONATE HCV) initiative. The authors demonstrated that preemptive administration of sofosbuvir $400 \mathrm{mg} / \mathrm{velpatas}$ vir $100 \mathrm{mg}$ once daily as a DAA regimen for 4 weeks immediately after transplantation could block viral replication in $\mathrm{HCV}$-mismatched recipients. The regimen was selected for its pangenotypic efficacy as well as a lack of interaction with immunosuppressive regimens. A total of 44 patients were enrolled (36 LTx and 8 HTx recipients). In 42 patients (95\%), HCV viral load was detected on NAT immediately after transplantation. All 35 patients who completed 6 months of follow-up survived and maintained excellent graft function. Viral load became undetectable at approximately 2 weeks after transplantation and the start of antiviral therapy and remained undetectable at 6 months. Compared with a cohort who received LTx from $\mathrm{HCV}^{-}$donors, more cases of acute cellular rejection requiring treatment occurred in HCV-mismatched recipients, but the difference was no longer significant after adjustment for possible confounders. ${ }^{24}$ This DONATE trial demonstrated that DAA treatment of $\mathrm{HCV}$-mismatched recipients prevented the establishment of HCV infection, allowing safe expansion of a currently inadequate thoracic organ donor pool. Finally, the authors pointed out that longer followup is needed so that the full potential risk-benefit profile of this intervention can be studied. In addition, data on the possible impact on chronic lung allograft dysfunction and cardiac allograft vasculopathy are needed.

\section{HOW TO DEAL WITH OFFERS FROM HCV ${ }^{+}$ DONORS FOR THORACIC ORGAN TRANSPLANTATION?}

In January 2017, the AST convened a meeting of experts in Dallas, Texas to review current data and to develop a framework for studying the use of $\mathrm{HCV}$ viremic organs in solid organ transplantation. The meeting concluded that the efficacy, safety, and tolerability of DAA therapy makes 
it feasible to study the transplantation of HCV viremic donors into $\mathrm{HCV}^{-}$recipients. There is an urgent need for funding to support well-designed, Institutional Review Board-approved research trials to prove the safety of using these organs in uninfected recipients, determine the optimal timing of DAA treatment, and improve the logistics associated with recovery and allocation. ${ }^{25}$

Thus, the authors of the DONATE HCV trial are to be applauded for conducting one of the first prospective singlecenter open-label trials of this approach. Longer-term data are needed to fully define the risks and benefits of this approach, and more studies should be conducted before HCV RNA ${ }^{+}$donors can be considered "acceptable risk" donors in solid organ transplantation. In particular, the effect of immediate DAA therapy on kidney function and the possible interaction with many other drugs administered early after HTx and LTx needs further study. In addition, the effect and impact of preemptive versus delayed treatment and short duration versus a full course of DAA therapy on $\mathrm{HCV}$ reactivation and consequences for patient outcomes awaits further study. Finally, investigation is needed of the possible negative effects of immune activation related to de novo viral infection on other unintended consequences, including organ rejection, other infections, and metabolic complications, as previously reported in HTx and LTx recipients from $\mathrm{HIV}^{+}$donors. These concerns warrant larger multicenter studies to investigate the safety of short- and long-term use of $\mathrm{HCV}$ viremic donors and DAA therapy.

\section{CONSENTING PATIENTS ON THE RISK OF A TRANSMISSIBLE DISEASE}

When successful thoracic organ transplantation started in the early 1980s, donor criteria were determined based on a consensus of the characteristics of the ideal donor. The evidence supporting such criteria was scanty and not based on randomized trials. Donor criteria have gradually evolved over nearly 4 decades to now include HTx and LTx from extended-criteria donors and from donors after circulatory death as standard practice in many countries. However, the evidence supporting the safe use of these organs comes mainly from single-center, retrospective series comparing different donor cohorts, and stronger evidence supporting the safe use of $\mathrm{HCV}^{+}$donors is needed. Until then, these donors should be used under strict conditions only with explicit patient informed consent on the status of the donor and education on necessary antiviral therapy after transplantation.

A recent study of the Organ Procurement and Transplantation Network database on organ utilization between 2010 and 2017 found significantly lower acceptance rates of adult kidneys, lungs, and pediatric hearts from $\mathrm{HIV}^{+}, \mathrm{HBV}^{+}$, or $\mathrm{HCV}^{+}$increased-risk donors compared with standard-risk donors. The authors concluded that educational efforts to standardize informed consent discussions of potential risks and benefits with patients/decision makers might improve organ utilization. ${ }^{10}$

The process of obtaining (written) informed consent for an intervention may vary among countries, as dictated by prevailing regulations and influenced by cultural differences in informing patients. When entering the transplant waiting list, recipients should preferably be informed and updated on the outcome after transplantation from different donor types. Risk factors should be explained so that any objection against a specific donor profile can be documented in the medical records.

Another interesting discussion is whether transplantation candidates should be informed explicitly of any increased risk at the time of donor offer. Should patients be offered the possibility to refuse the offer and wait for the next donor? In our experience, most transplantation candidates leave the final decision of whether or not to accept the organ up to the physician. In daily transplantation practice, accepting a specific organ offer for an individual candidate always involves balancing the risk inherent to the donor's profile versus the risk of premature death of the sick patient while on the waiting list.

\section{CONCLUSIONS}

The use of HCV-infected donors is an evolving strategy to expand the thoracic organ pool. Owing to the rapid advances in antiviral agents, the potential of this specific donor category is appealing, but the systematic use of these organs needs further study.

Until more evidence on the safe use of these increasedrisk donors becomes available, extensive and written informed consent should be obtained from candidates entering the waiting list, and they should be made aware of the need for antiviral therapy. However, finally the risk of being infected with a transmissible disease should be balanced against the risk of dying prematurely.

\section{Conflict of Interest Statement}

Authors have nothing to disclose with regard to commercial support.

\section{References}

1. Khush KK, Cherikh WS, Chambers DC, Goldfarb S, Hayes D Jr, Kucheryavaya AY, et al. The international thoracic organ transplant registry of the International Society for Heart and Lung Transplantation: thirty-fifth adult heart transplantation report-2018; focus theme: multiorgan transplantation. $J$ Heart Lung Transplant. 2018;37:1155-68.

2. Chambers DC, Cherikh WS, Goldfarb SB, Hayes D Jr, Kucheryavaya AY, Toll AE, et al. The international thoracic organ transplant registry of the International Society for Heart and Lung Transplantation: thirty-fifth adult lung and heart-lung transplant report-2018; focus theme: multiorgan transplantation. $J$ Heart Lung Transplant. 2018;37:1169-83.

3. Colvin M, Smith JM, Hadley N, Skeans MA, Uccellini K, Lehman R, et al. OPTN/SRTR 2017 annual data report: heart. Am J Transplant. 2019;19(Suppl 2):323-403.

4. Valapour M, Lehr CJ, Skeans MA, Smith JM, Uccellini K, Lehman R, et al. OPTN/SRTR 2017 annual data report: lung. Am J Transplant. 2019;19(Suppl 2):404-84. 
5. Berg K, Clemmensen TS, Tram EM, Koefoed-Nielsen P, Ilkjaer LB, Poulsen SH, et al. Survival, graft function, and incidence of allograft vasculopathy in heart transplant recipients receiving adverse risk profile donor hearts. Clin Transplant. 2018;32:e13343.

6. Somers J, Ruttens D, Verleden SE, Cox B, Stanzi A, Vandermeulen E, et al. A decade of extended-criteria lung donors in a single center: was it justified? Transplant Int. 2015;28:170-9.

7. Date H. Living-related lung transplantation. J Thorac Dis. 2017;9:3362-71.

8. Ceulemans LJ, Inci I, Van Raemdonck D. Lung donation after circulatory death. Curr Opin Organ Transplant. 2019;24:288-96.

9. Beaupré RA, Morgan JA. Donation after cardiac death: a necessary expansion for heart transplantation. Semin Thorac Cardiovasc Surg. 2019;31:721-5.

10. Sapiano MRP, Jones JM, Bowman J, Levi ME, Basavaraju SV. Impact of US Public Health Service increased risk deceased donor designation on organ utilization. Am J Transplant. 2019;19:2560-9.

11. Phillips KG, Ranganath NK, Malas J, Lonze BE, Gidea CG, Smith DE, et al. Impact of the opioid epidemic on heart transplantation: donor characteristics and organ discard. Ann Thorac Surg. 2019;108:1133-9.

12. Zamora MR, Nicolls MR, Hodges TN, Marquesen J, Astor T, Grazia T, et al. Following universal prophylaxis with intravenous ganciclovir and cytomegalovirus immune globulin, valganciclovir is safe and effective for prevention of CMV infection following lung transplantation. Am J Transplant. 2004;4: $1635-42$.

13. Blumberg EA, Rogers CC. Solid organ transplantation in the HIVinfected patient: guidelines from the American Society of Transplantation infectious diseases community of practice. Clin Transplant. 2019; 33:e13499.

14. Huprikar S, Danziger-Isakov L, Ahn J, Naugler S, Blumberg E, Avery RK, et al. Solid organ transplantation from hepatitis B virus-positive donors: consensus guidelines for recipient management. Am J Transplant. 2015;15: 1162-72.

15. White SL, Rawlinson W, Boan P, Sheppeard V, Wong G, Waller K, et al. Infectious disease transmission in solid organ transplantation: donor evaluation, recipient risk, and outcomes of transmission. Transplant Direct. 2018;5:e416.
16. Goldberg DS, Abt PL, Blumberg EA, Van Deerlin VM, Levine M, Reddy KR et al. Trial of transplantation of $\mathrm{HCV}$-infected kidneys into uninfected recipients N Engl J Med. 2017;376:2394-5.

17. Durand CM, Bowring MG, Brown DM, Chattergoon MA, Massaccesi G, Bair N et al. Direct-acting antiviral prophylaxis in kidney transplantation from hepatitis $\mathrm{C}$ virus-infected donors to noninfected recipients: an open-label nonrandomized trial. Ann Intern Med. 2018;168:533-40.

18. Selzner N, Berenguer M. Should organs from hepatitis C-positive donors be used in hepatitis C-negative recipients for liver transplantation? Liver Transpl. 2018; 24:831-40.

19. Trotter PB, Summers DM, Ushiro-Lumb I, Robb M, Bradley JA, Powell J, et al Use of organs from hepatitis $C$ virus-positive donors for uninfected recipients: a potential cost-effective approach to save lives? Transplantation. 2018;102: 664-72.

20. Frager SZ, Dhand A, Gass A, Levine A, Spielvogel D, Nog R, et al. Heart transplantation for hepatitis $\mathrm{C}$ virus non-viremic recipients from hepatitis $\mathrm{C}$ virus viremic donors. Cardiol Rev. 2019;27:179-81.

21. Schlendorf KH, Zalawadiya S, Shah AS, Wigger M, Chung CY, Smith S, et al. Early outcomes using hepatitis C-positive donors for cardiac transplantation in the era of effective direct-acting anti-viral therapies. J Heart Lung Transplant. 2018:37:763-9.

22. Abdelbasit A, Hirji A, Halloran K, Weinkauf J, Kapasi A, Lien D, et al. Lung transplantation from hepatitis $\mathrm{C}$ viremic donors to uninfected recipients. Am J Respir Crit Care Med. 2018;197:1492-6.

23. Radzi Y, Shezad MF, Danziger-Isakov L, Morales DLS, Zafar F. Utilizing hepatitis C and B virus infected donor organs for pediatric heart transplantation. J Thorac Cardiovasc Surg. 2019;158:548-53.

24. Woolley AE, Singh SK, Goldberg HJ, Mallidi HR, Givertz MM, Mehra MR, et al Heart and lung transplants from HCV-infected donors to uninfected recipients. $N$ Engl J Med. 2019;380:1606-17.

25. Levitsky J, Formica RN, Bloom RD, Charlton M, Curry M, Friedewald J, et al. The American Society of Transplantation consensus conference on the use of hepatitis $\mathrm{C}$ viremic donors in solid organ transplantation. Am J Transplant. 2017; 17:2790-802 